\title{
Cross effects of the strain of dietary Saccharomyces cerevisiae and rearing conditions on the onset of intestinal microbiota and digestive enzymes in rainbow trout, Onchorhynchus mykiss, fry
}

\author{
Yann Wachéa ${ }^{\underline{a}}$, Françoise Auffray ${ }^{\underline{a}}$, François-Joël Gatesoupe ${ }^{\underline{a}}{ }^{\text {, }}$, José Zambonino ${ }^{\underline{a}}$, Vincent \\ Gayet $\underline{\underline{b}}$, Laurent Labbé ${ }^{\underline{b}}$ and Claire Quentel ${ }^{\underline{c}}$
}

\author{
a INRA-Ifremer, UMR Nutrition Aquaculture et Génomique, Centre de Brest, BP 70, 29280 Plouzané, France \\ b Pisciculture Expérimentale INRA des Monts d'Arrée (PEIMA), Barrage du Drennec, BP17, 29450 Sizun, France \\ c AFSSA site de Brest, Laboratoire d'Etudes et de Recherches en Pathologie des Poissons, Technopole Brest \\ Iroise, BP 70, 29280 Plouzané, France \\ *: Corresponding author : joel.gatesoupe@ifremer.fr
}

\begin{abstract}
Two strains of Saccharomyces cerevisiae were tested as probiotics for rainbow trout fry, during the first month of feeding. Each strain was introduced into separate diets, at the rate of 106 CFU g- 1 and their effects were compared with those of a control diet. Two rearing conditions were simultaneously compared, to test the adaptability of the probiotic treatment. From start feeding onwards, the water supply came from either spring or river, resulting in two different temperature ranges, 11-11.5 and 7-8 ${ }^{\circ} \mathrm{C}$ respectively. Growth and development were optimal in spring water, while some delay was observed with colder river water. A slight but significant increase in mortality was also observed in the river group. In all groups, the counts of bacteria associated with trout intestine were maximum 10 days post start feeding (dpsf; $107 \mathrm{CFU} g-1$ ). The counts of probiotic yeast were also maximum at $10 \mathrm{dpsf}$ (104-105 CFU g- 1), but the decrease was slower in river than in spring water. An autochthonous yeast, Debaryomyces hansenii, was also retrieved associated to the intestine of the control group in high numbers after 240 degree days of experiment (104-105 CFU $g-1$ ), while the colonization level was significantly less in trout fed the probiotic diets. The effect of the dietary yeast was observed by assaying the activity of three enzymes in the brush border membrane of the enterocytes: alkaline phosphatase (AP), y-glutamyl-transpeptidase (GGT), and leucine-aminopeptidase $\mathrm{N}(\mathrm{LAP})$. At 10 and $20 \mathrm{dpsf}$, the trout reared in spring water had higher activities of the three enzymes when they were fed the strain S. cerevisiae var. boulardii, suggesting an earlier maturation of the digestive system in this group, compared with trout fed either the other strain of S. cerevisiae or the control diet. The effect was not observed in trout reared in river water with slower growth. Both S. boulardii and $\mathrm{D}$. hansenii seemed to stimulate digestive maturation in fish, but the natural colonization by $\mathrm{D}$. hansenii was likely too late for trout reared at optimal temperature. The supplementation of trout starter diet with $\mathrm{S}$. boulardii may be particularly useful in fast growing conditions.
\end{abstract}

Keywords: Start feeding; Larval development; Gut maturation; Brush border membrane; Yeast; Debaryomyces hansenii 


\section{Introduction}

Many probiotic bacteria have been proposed to improve health in rainbow trout. The strains were generally antagonistic to pathogens (Jöborn et al., 1997; Gram et al., 1999; Robertson et al., 2000; Spanggaard et al., 2001; Irianto and Austin, 2002; Aubin et al., 2005a), and an important feature was the ability to colonise fish gut (Jöborn et al., 1997; Nikoskelainen et al., 2001a, b). The immune system was stimulated in rainbow trout by several probiotics (Irianto and Austin, 2002; Nikoskelainen et al., 2003; Raida et al., 2003; Panigrahi et al., 2004). Inactivated bacterial cells might be also efficient to control furunculosis, but the viability of the probiotics influenced the immune response (Irianto and Austin, 2003; Panigrahi et al., 2005).

Andlid et al. (1995) suggested that yeast isolated from rainbow trout might also improve health, with a particular attention to their colonisation potential. Like probiotic bacteria, Saccharomyces cerevisiae var. boulardii acted as pathogen antagonist and immunomodulator in mammals (McFarland and Bernasconi, 1993), but the yeast increased also the specific and total activities of digestive enzymes in the brush-border membrane (BBM; Buts et al., 1986, 1999). S. cerevisiae var. boulardii had some effect on rainbow trout metabolism, since the dietary supply of the yeast increased muscle lipids and red pigmentation, while improving the resistance of trout to Yersinia ruckeri (Aubin et al., 2005b; Quentel et al., 2005). It seems that the probiotic efficiency of $S$. cerevisiae is dependent on the strain (Fietto et al., 2004; Van der Aa Kühle et al., 2005).

Considering the presence of autochthonous yeast with probiotic potential in trout intestine, a dietary supply of allochthonous strains might seem worthless. Aubin et al. (2005a) hypothesised that autochthonous Debaryomyces hansenii could stimulate the mucosal metabolism in rainbow trout intestine, while interfering with the dietary yeast. However, the occurrence of autochthonous yeast was different in several locations (Gatesoupe et al., 2005a). More generally, the intestinal microbiota of rainbow trout was highly variable in time, and between farms (Spanggaard et al., 2000; Huber et al., 2004; Gatesoupe et al., 2005a, b). Some environmental conditions may account for this variability, for instance the rearing temperature (Lésel, 1990). Consequently, probiotics may serve as a precaution in front of this variability, but at the same time, the efficiency of the treatments should be validated in several rearing conditions.

The present experiment was conducted on rainbow trout fry at start feeding, to compare the effects of two probiotic strains of S. cerevisiae, in combination with the cross effects of two rearing conditions, with particular attention to intestinal microbiota, and to the activity of BBM enzymes in trout enterocytes. The effects of the strain already tested on rainbow trout (Aubin et al., 2005a, b) were compared to those of another strain, which was recommended by Lara-Flores et al. (2003) as growth promoter for Nile tilapia.

\section{Materials and methods}

\subsection{Rearing conditions and diets}

The strain of rainbow trout (Oncorhynchus mykiss), and the general rearing conditions were as described by Aubin et al. (2005a), but two water qualities were compared in the present experiment. All the eggs were incubated and hatched in UV-treated spring water (11.54 \pm $0.02^{\circ} \mathrm{C}$, mean \pm standard error). Ten days post hatching, the fry were dispatched in 18 tanks. Nine tanks were kept receiving UV-treated spring water, while in the nine other tanks, the water supply was shifted to filtered river water within $5 \mathrm{~h}$, resulting in a temperature decrease 
from 11.4 to $7.2^{\circ} \mathrm{C}$. Then the two conditions differed in their temperature ranges, $11-11.5$ and $7-8^{\circ} \mathrm{C}$ for the spring and the river, respectively.

The diets were prepared with Ecostart ${ }^{\circledR} 15$, crumble size ' 01 '. The control diet was obtained by coating the pellets with cod liver oil $\left(32 \mathrm{ml} \mathrm{kg}^{-1}\right)$. Two experimental diets SC and SB were prepared with the probiotic yeast Saccharomyces cerevisiae strain NCYC Sc 47/g (National Collection of Yeast Culture, Norwich, UK), or Saccharomyces cerevisiae var. boulardii CNCM I-1079 (S. boulardii, Institut Pasteur, Paris, France), respectively. Both strains were obtained as commercial preparations, Biosaf ${ }^{\circledR}$ Sc 47 and Levucell ${ }^{\circledR}$ SB20, respectively. The active dried yeast preparations were powdered by grinding and sifting through $100 \mu \mathrm{m}$, then suspended in cod liver oil. The amounts of powder were adjusted in the oily suspensions to obtain a final concentration of ca. $10^{6}$ Colony Forming Units (CFU) of yeast per $g$ of experimental diet, after the pellets had been coated with the shaken suspensions $\left(32 \mathrm{ml} \mathrm{kg}^{-1}\right)$. After coating, the actual counts of yeast on Sabouraud agar with antibiotics (Aubin et al. 2005a) were $(7 \pm 3) \times 10^{5}$ and $(9 \pm 1) \times 10^{5} \mathrm{CFU} \mathrm{g}^{-1}$ of $S$. cerevisiae (diet SC) and $S$. boulardii (diet $\mathrm{SB}$ ), respectively (mean \pm standard error).

One day before start feeding, the fry weighed $60 \mathrm{mg}$, and they were dispatched in three tanks per treatment, i.e. the three diets crossed with the two water qualities. At start feeding, $423 \pm 2$ fish were counted per tank, without any significant difference. The trout were weighed at 23 days post start feeding (dpsf), then at 37 dpsf.

\subsection{Fish dissection, microbiology, and enzymatic assays}

Six fish were sampled in each tank one day before start feeding, then at 10, 20, and $31 \mathrm{dpsf}$, after $20 \mathrm{~h}$ of starvation. After euthanasia and dissection of the intestine, three fish were used for microbiological examination, and the cultivable bacteria and yeast associated with the intestine were counted and characterised by the methods of Aubin et al. (2005a). Briefly, hindgut sections were homogenised, diluted and spread on Petrifilm and Sabouraud agar with antibiotics, to count bacteria and yeast, respectively. After phenotypic characterization with the API system, the 16S rRNA genes were characterised with restriction enzymes, and those corresponding to the dominant genotypes were partially sequenced. The three other fish were used for enzymatic measurements, according to the methods mentioned by Zambonino Infante and Cahu (1999). Three enzymes were assayed in BBM: alkaline phosphatase (AP), $\gamma$ glutamyl-transpeptidase (GGT), and leucine-amino-peptidase N (LAP). The maturation of the enterocytes is described by expressing the activities of the BBM enzymes as a ratio to a cytosolic enzyme, leucine-alanine peptidase (Leu-Ala).

\subsection{Statistical analysis}

The mortality was arcsine square root transformed, whereas the bacterial counts were log transformed. The normality and homogeneity of all the data were checked with the tests of Kolmogorov-Smirnov and Bartlett, respectively. When the data passed the tests, they were compared by two-way analysis of variance (ANOVA), followed by the Student-NewmanKeuls test. Otherwise, they were compared by the Kruskal-Wallis test, followed by the Dunnett's method. 


\section{Results}

Though mortality was low, the survival of trout kept in spring water was significantly higher than that of the other group by the end of the experiment (97.1 $\pm 0.4 \%$ vs. $95.5 \pm 0.4 \%$, $P=0.01)$. No cannibalism was observed. Growth was strongly different between the fish reared with the two water qualities, due to temperature gap. At 23 dpsf, the trout reared in spring water weighed $605 \pm 6 \mathrm{mg}$, while those reared in river water weighed $312 \pm 3 \mathrm{mg}$ (mean \pm standard error). At $37 \mathrm{dpsf}$, the mean weights were $1293 \pm 20$ and $547 \pm 2 \mathrm{mg}$ for the groups reared in spring and river water, respectively. Neither survival nor growth was significantly affected by the probiotic treatment.

\subsection{Intestinal microbiota}

The bacterial counts in trout intestine were not significantly different among treatments (Fig $1 \mathrm{~A}$ and $1 \mathrm{~B}$ ). One day before start feeding, ca. $10^{4} \mathrm{CFU} \mathrm{g}^{-1}$ were retrieved in the intestine. The counts were maximum at $10 \mathrm{dpsf}\left(10^{7} \mathrm{CFU} \mathrm{g}{ }^{-1}\right)$, then they decreased by the end of the first month $\left(10^{2}-10^{4} \mathrm{CFU} \mathrm{g}^{-1}\right)$.

There was no clear effect of the probiotics on intestinal bacteria, but in trout kept in spring water, the bacterial diversity seemed more marked than in trout reared in river water (Fig 1C and 1D). This was observed as early as one day before feeding, $20 \mathrm{~h}$ after shifting temperature. At this date, Rhodococcus sp. (Table 1) was dominant in trout transferred in river water. The strain was also present in the group kept in spring water, but with other dominant bacteria, Aeromonas sp. PL2A1 and Flavobacterium sp. Aeromonas sp. PL2D1 was dominant at $10 \mathrm{dpsf}$ in both groups, then at 20 dpsf in the river group. Pseudomonas sp. was observed in both groups at all dates, but the strain was strongly dominant in the river group at 31 dpsf.

The probiotic yeasts were retrieved associated with the intestine in high numbers at $10 \mathrm{dpsf}$ $\left(10^{4}-10^{5} \mathrm{CFU} \mathrm{g}^{-1}\right.$; Fig $2 \mathrm{~A}$ and $\left.2 \mathrm{~B}\right)$. The counts were still high in the river group at $20 \mathrm{dpsf}$, while the population decreased to ca. $10^{3} \mathrm{CFU} \mathrm{g}^{-1}$ in the spring water group. At $31 \mathrm{dpsf}$, the counts were irregular, and no colony was detected in the group SC in spring water.

An autochthonous strain of Debaryomyces hansenii YB3A3 was also observed, as already noted in previous experiments (Aubin et al., 2005a; Gatesoupe et al., 2005a). The association with the intestine was maximum with the control diet at 20 and 31 dpsf in the spring water and river groups, respectively $\left(10^{4}-10^{5} \mathrm{CFU} \mathrm{g}^{-1}\right.$; Fig $2 \mathrm{C}$ and $\left.2 \mathrm{D}\right)$. The rearing temperature seemed determinative, and considering that similar numbers of degree days were cumulated at 20 dpsf in the spring water group, and at 31 dpsf in the river group (239 and 243 degree days, respectively), the counts of the autochthonous yeast were compared among dietary treatments at ca. 240 degree days. Even after log transformation the normality test failed, and it was not possible to use the two-way ANOVA. By pooling the replicates fed the same diet till 240 degree days, while disregarding water quality, the Kruskal-Wallis test indicated a significant difference $(P<0.05)$. The counts in the groups fed the probiotics were found significantly lower than the counts in the control group with the Dunnett's method.

\subsection{Enzymatic activities}

In the spring water group, the specific activity of the three BBM enzymes was significantly higher with diet SB at 10 and 20 dpsf, except for leucine aminopeptidase at 20 dpsf, but the trend was similar (Fig 3). This was no longer observed at 31 dpsf, nor was it observed at any 
sampling date in the river group. In this latter group, the activity of the three enzymes was more intense with the control diet at 20 dpsf, and also at the other dates for GGT.

The segmental activity of the three BBM enzymes was expressed as a ratio to Leu-Ala peptidase activity (Fig 4). The spring water group exhibited higher ratios than the river group for the three enzymes at $10 \mathrm{dpsf}(P<0.001)$, then at $20 \mathrm{dpsf}(P<0.05)$. At $31 \mathrm{dpfs}$ the AP/LeuAla and LAP/leu-Ala ratios were still higher in the spring water group $(P<0.05)$, but the difference was not significant for GGT. An effect of the diet on enterocyte maturation was noted in spring water. At $10 \mathrm{dpsf}$, the LAP/Leu-Ala ratio obtained with diet SB was significantly greater than with the other treatments. The same trend was observed with the two other enzymes, though the differences were not significant. At 20 dpsf, the trend was still observed with alkaline phosphatase, but it disappeared at $31 \mathrm{dpsf}$. Some significant differences were also observed in the river group, but without suggesting any general trend.

\section{Discussion}

The difference in temperature strongly affected fish growth and metabolism. The effect on intestinal bacteria was less marked, since the counts were similar at each sampling date. In spite of UV treatment, the bacteria associated with the group maintained in spring water were more diverse than those of the group reared in river water. This might be due to the presence of a limited number of psychrophilic strains, while some other ones, still active at $11^{\circ} \mathrm{C}$, would become nonculturable after the decrease in temperature. For instance, Aeromonas sp. PL2A1 was not retrieved $20 \mathrm{~h}$ after shifting temperature, possibly entering into the viable but nonculturable state below $10^{\circ} \mathrm{C}$, like Vibrio vulnificus (Oliver et al., 1991).

The effect of temperature was more visible with yeast than with bacteria. The massive association of yeast with the intestine seemed limited to the first month of feeding in previous experiments (Aubin et al., 2005a; Gatesoupe et al., 2005a, b). The decrease in counts of the probiotic strains was delayed in the river group, concomitantly with the delayed trout development. This decrease was observed in both groups when 240 degree dpsf were cumulated, which corresponded to the maximum of intestinal colonisation by autochthonous D. hansenii in trout fed the control diet. This maximum was not reached in trout fed the probiotic diets, suggesting a competition for space between $D$. hansenii and $S$. cerevisiae. Dietary S. cerevisiae var. boulardii increased the activities of BBM enzymes at 10 and 20 dpsf in trout kept in spring water, while the other dietary yeast did not. S. boulardii stimulated BBM enzyme activities in mammals (Buts et al., 1986, 1999), but there was no such report with other biovars of $S$. cerevisiae. A strain isolated from rainbow trout intestine, Debaryomyces hansenii HF1, stimulated amylase secretion and the activity of BBM enzymes in larval sea bass, whereas S. cerevisiae X2180 did not (Tovar et al., 2002). However, some probiotic traits are not specific to $S$. boulardii (Brandao et al., 1998). Growth yield, and resistance to thermal and acidic stresses might be important characteristics of the probiotic strains (Fietto et al., 2004). Adhesiveness did not appear as an essential condition, even though the prerequisites for probiotic yeast have not been clearly identified (Van der Aa Kühle et al., 2005). In sea bass larvae, the colonisation potential could not explain the differences observed between the effects of D. hansenii HF1 and S. cerevisiae X2180, while the amounts of polyamines produced by the yeast were suspected to play a role (Tovar et al., 2002). The probiotic effects of $D$. hansenii HF1 on sea bass larvae were further confirmed by Tovar-Ramírez et al. (2004). When the diet was supplemented with a suitable amount of the yeast, the sea bass larvae grew faster, with an accelerated pancreatic and intestinal maturation, while survival and conformation were improved. The case of rainbow trout is different because the fry are much more developed than sea bass at first feeding. In the present experiment, the early intestinal maturation of rainbow trout was observed at $10 \mathrm{dpfs}$, but only 
when trout fed $S$. boulardii were kept in spring water. The river temperature was likely below the optimum for trout development, and the probiotic yeast did not appear efficient in that condition. D. hansenii YB3A3 colonised naturally the intestine, but not so early as the probiotic yeast, which was brought in high numbers since start feeding. This delay may explain why S. boulardii had an effect on BBM activity till $20 \mathrm{dpsf}$ in the spring water group, while the colonisation level of $D$. hansenii was not sufficient yet.

No clear effect was observed in the present experiment with the strain of $S$. cerevisiae that improved growth of Nile tilapia juveniles (Lara-flores et al., 2003). However, the long term effects of the yeast should be further investigated. The supplementation of trout starter diet with $S$. boulardii may be particularly useful in fast growing conditions, where it would be necessary to stimulate the precocious maturation of the digestive function (Tovar et al., 2004). However, this effect was dependent on the rearing conditions, and it should be tested in other locations, especially in those where $D$. hansenii has not been detected. The practical interest of such confirmation lies in regulatory aspects. The authorization of $D$. hansenii as probiotic for fish may be less easy to obtain than that of $S$. cerevisiae strains, which are currently used for mammals.

\section{References}

Andlid, T., Juárez, R.V., Gustafsson, L., 1995. Yeast colonizing the intestine of rainbow trout (Salmo gairdneri) and turbot (Scophthalmus maximus). Microb. Ecol. 30, 321-334.

Aubin, J., Gatesoupe, F.J., Labbé, L., Lebrun, L., 2005a. Trial of probiotics to prevent the vertebral column compression syndrome in rainbow trout (Oncorhynchus mykiss Walbaum). Aquacult. Res. 36, 758-767.

Aubin, J., Gatesoupe, F.J., Quentel, C., Labbé, L., Forraz, M., 2005b. Ofimer probiotic study on rainbow trout. III. Flesh quality assessment of rainbow trout (Oncorhynchus mykiss) submitted to probiotic treatment with Saccharomyces cerevisiae var. boulardii. In: Howell, B., Flos, R. (Eds.), Lessons from the Past to Optimise the Future, Aquaculture Europe 2005, Trondheim, Norway, 5-9 August 2005. EAS Special Publication No. 35, Oostende, Belgium, pp. 115-116.

Brandao, R.L., Castro, I.M., Bambirra, E.A., Amaral, S.C., Fietto, L.G., Tropia, M.J.M., Neves, M.J., Dos Santos, R.G., Gomes, N.C.M., Nicoli, J.R., 1998. Intracellular signal triggered by cholera toxin in Saccharomyces boulardii and Saccharomyces cerevisiae. Appl. Environ. Microbiol. 64, 564-568.

Buts, J.P., Bernasconi, P., Van Craynest, M.P., Maldague, P., De Meyer, R., 1986. Response of human and rat small intestinal mucosa to oral administration of Saccharomyces boulardii. Pediatr. Res. 20, 192-196.

Buts, J.P., De Keyser, N., Marandi, S., Hermans, D., Sokal, E.M., Chae, Y.H., Lambotte L., Chanteux, H., Tulkens, P.M., 1999. Saccharomyces boulardii upgrades cellular adaptation after proximal enterectomy in rats. Gut 45, 89-96.

Fietto, J.L.R., Araujo, R.S., Valadao, F.N., Fietto, L.G., Brandao, R.L., Neves, M.J., Gomes, F.C.O., Nicoli, J.R., Castro, I.M., 2004. Molecular and physiological comparisons between Saccharomyces cerevisiae and Saccharomyces boulardii. Can. J. Microbiol. 50, 615-621.

Gatesoupe, F.J., Aubin, J., Quentel, C., Labbé, L., 2005a. Ofimer probiotic study on rainbow trout. IV. The settlement of intestinal microbiota in rainbow trout (Oncorhynchus mykiss) fry submitted to probiotic treatment. In: Hendry, C.I., Van Stappen, G, Wille, M., Sorgeloos, P. (Eds.), Larvi 2005, $4^{\text {th }}$ Fish \& Shellfish Larviculture Symposium, 5-8 September 2005, Ghent university, Gent, Belgium. EAS Special Publication No. 36, Oostende, Belgium, pp. 180-183. 
Gatesoupe, F.J., Aubin, J., Quentel, C., Labbé, L., Forraz, M., 2005b. Ofimer pobiotic study on rainbow trout. II. Intestinal microbiota in rainbow trout (Oncorhynchus mykiss) submitted to probiotic treatment with Saccharomyces cerevisiae var. boulardii. In: Howell, B., Flos, R. (Eds.), Lessons from the Past to Optimise the Future, Aquaculture Europe 2005, Trondheim, Norway, 5-9 August 2005. EAS Special Publication No. 35, Oostende, Belgium, pp. 217-218.

Gram, L., Melchiorsen, J., Spanggaard, B., Huber, I., Nielsen, T.F., 1999. Inhibition of Vibrio anguillarum by Pseudomonas fluorescens AH2, a possible probiotic treatment of fish. Appl. Environ. Microbiol. 65, 969-973.

Huber, I., Spanggaard, B., Appel, K.F., Rossen, L. Nielsen, T., Gram, L., 2004. Phylogenetic analysis and in situ identification of the intestinal microbial community of rainbow trout (Oncorhynchus mykiss, Walbaum). J. Appl. Microbiol. 96, 117-132.

Irianto, A., Austin, B., 2002. Use of probiotics to control furunculosis in rainbow trout, Oncorhynchus mykiss (Walbaum). J. Fish Dis. 25, 333-342.

Irianto, A., Austin, B., 2003. Use of dead probiotic cells to control furunculosis in rainbow trout, Oncorhynchus mykiss (Walbaum). J. Fish Dis. 26, 59-62.

Jöborn, A., Olsson, J.C., Westerdahl, A., Conway, P.L., Kjelleberg, S., 1997. Colonization in the fish intestinal tract and production of inhibitory substances in intestinal mucus and faecal extracts by Carnobacterium sp. strain K1. J. Fish Dis. 20, 383-392.

Lara-Flores, M., Olvera-Novoa M.A., Guzmán-Méndez, B.E., López-Madrid, W., 2003. Use of the bacteria Streptococcus faecium and Lactobacillus acidophilus, and the yeast Saccharomyces cerevisiae as growth promoters in Nile tilapia (Oreochromis niloticus). Aquaculture 216, 193-201.

Lésel, R., 1990. Thermal effect on bacterial flora in the gut of rainbow trout and African catfish. In: Lésel, R. (Ed.) Microbiology in Poecilotherms, Proceedings of the International Symposium on Microbiology in Poecilotherms, 10-12 July 1989, Paris, France. Elsevier, Amsterdam, pp. 33-38.

McFarland, L.V., Bernasconi, P., 1993. Saccharomyces boulardii: a review of an innovative biotherapeutic agent. Microb. Ecol. Health D. 6, 157-171.

Nikoskelainen, S., Salminen, S., Bylund, G., Ouwehand, A.C., 2001a. Characterization of the properties of human- and dairy-derived probiotics for prevention of infectious diseases in fish. Appl. Environ. Microbiol. 67, 2430-2435.

Nikoskelainen, S., Ouwehand, A., Salminen, S., Bylund, G., 2001b. Protection of rainbow trout (Oncorhynchus mykiss) from furunculosis by Lactobacillus rhamnosus. Aquaculture 198, 229-236.

Nikoskelainen, S., Ouwehand, A.C., Bylund, G., Salminen, S., Lilius, E.M., 2003. Immune enhancement in rainbow trout (Oncorhynchus mykiss) by potential probiotic bacteria (Lactobacillus rhamnosus). Fish Shellfish Immunol. 15, 443-452.

Oliver, J.D., Nilsson, L., Kjelleberg, S., 1991. Formation of nonculturable Vibrio vulnificus cells and its relationship to the starvation state. Appl. Environ. Microbiol. 57, 2640-2644.

Panigrahi, A., Kiron, V., Kobayashi, T., Puangkaew, J., Satoh, S., Sugita, H., 2004. Immune responses in rainbow trout Oncorhynchus mykiss induced by a potential probiotic bacteria Lactobacillus rhamnosus JCM 1136. Vet. Immunol. Immunopathol. 102, 379-388.

Panigrahi, A., Kiron, V., Kobayashi, T., Puangkaew, J., Satoh, S., Sugita, H., 2005. The viability of probiotic bacteria as a factor influencing the immune response in rainbow trout Oncorhynchus mykiss. Aquaculture 243, 241-254.

Quentel, C., Gatesoupe, F.J., Aubin, J., Lamour, F., Abiven, A., Baud, M., Labbé, L., Forraz, M., 2005. Ofimer probiotic study on rainbow trout . I. Resistance against Yersinia ruckeri and humoral immune response of rainbow trout (Oncorhynchus mykiss) submitted to probiotic treatment with Saccharomyces cerevisiae var. boulardii. In: 
Howell, B., Flos, R. (Eds.), Lessons from the Past to Optimise the Future, Aquaculture Europe 2005, Trondheim, Norway, 5-9 August 2005. EAS Special Publication No. 35, pp. 380-381.

Raida, M.K., Larsen, J.L., Nielsen, M.E., Buchmann, K., 2003. Enhanced resistance of rainbow trout, Oncorhynchus mykiss (Walbaum), against Yersinia ruckeri challenge following oral administration of Bacillus subtilis and B. licheniformis (BioPlus2B). J. Fish Dis. 26, 495-498.

Robertson, P.A.W., O'Dowd, C., Burrells, C., Williams, P., Austin, B., 2000. Use of Carnobacterium sp. as a probiotic for Atlantic salmon (Salmo salar L.) and rainbow trout (Oncorhynchus mykiss, Walbaum). Aquaculture 185, 235-243.

Spanggaard, B., Huber, I., Nielsen, J., Nielsen, T., Appel, K.F., Gram, L., 2000. The microflora of rainbow trout intestine: a comparison of traditional and molecular identification. Aquaculture 182, 1-15.

Spanggaard, B., Huber, I., Nielsen, J., Sick, E.B., Pipper, C.B., Martinussen, T., Slierendrecht, W.J., Gram, L., 2001. The probiotic potential against vibriosis of the indigenous microflora of rainbow trout. Environ. Microbiol. 3, 755-765.

Tovar, D., Zambonino, J., Cahu, C., Gatesoupe, F.J., Vázquez-Juárez, R., Lésel, R., 2002. Effect of live yeast incorporation in compound diet on digestive enzyme activity in sea bass larvae. Aquaculture 204, 113-123.

Tovar-Ramírez, D., Zambonino Infante, J., Cahu, C., Gatesoupe, F.J., Vázquez-Juárez, R., 2004. Influence of dietary live yeast on European sea bass (Dicentrarchus labrax) larval development. Aquaculture 234, 415-427.

Van der Aa Kühle, A., Skovgaard, K., Jespersen, L., 2005. In vitro screening of probiotic properties of Saccharomyces cerevisiae var. boulardii and food-borne Saccharomyces cerevisiae strains. Int. J. Food Microbiol. 101, 29-39.

Zambonino Infante, J.L., Cahu, C.L., 1999. High dietary lipid levels enhance digestive tract maturation and improve Dicentrarchus labrax larval development. J. Nutr. 129, 11951200. 
Table 1 - Identification of the dominant strains isolated in rainbow trout intestine, with partial sequences of 16S ribosomal RNA gene referenced in nucleotide databases; the identical fragments can be retrieved by reading the published sequences from the first nucleotide to the last one indicated in the last two columns.

\begin{tabular}{|c|c|c|c|c|c|c|}
\hline \multirow{2}{*}{$\begin{array}{l}\text { Dominant } \\
\text { Strain }\end{array}$} & \multicolumn{3}{|c|}{ Reference strain in GenBank } & \multicolumn{3}{|c|}{ Identical $16 \mathrm{~S}$ gene fragment } \\
\hline & Genus & Species & Accession $n^{\circ}$ & Fragment length (bp) & From & To \\
\hline 5R020 & Rhodococcus & erythropolis & $\underline{\text { AF532870 }}$ & 667 & 1371 & 705 \\
\hline $5 \mathrm{~S} 035$ & Flavobacterium & sp. IsoA1 & $\underline{\mathrm{AJ} 319015}$ & 533 & 148 & 680 \\
\hline AFT112 & Pseudomonas & sp. TB2-1-II & $\underline{\text { AY599711 }}$ & 771 & 16 & 786 \\
\hline PL2A1 & Aeromonas & salmonicida & $\underline{\text { AF200329 }}$ & 821 & 119 & 939 \\
\hline PL2D1 & Aeromonas & sobria & $\underline{\mathrm{X} 74683}$ & 670 & 151 & 920 \\
\hline
\end{tabular}



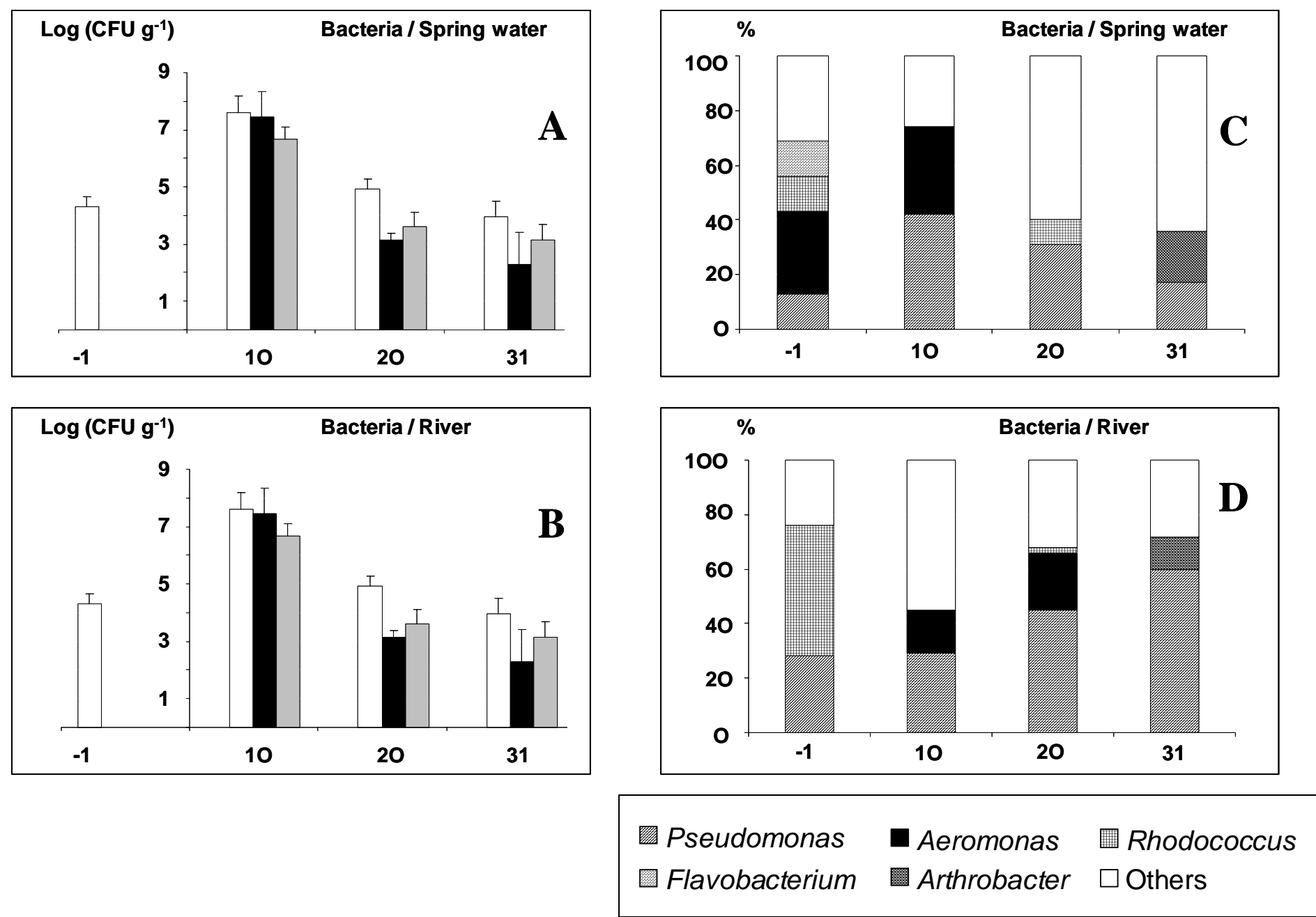

Fig. 1. Left: counts of bacteria associated with the intestine of rainbow trout at $-1,10$, 20, and 31 dpsf in $\log \left(\mathrm{CFU} \mathrm{g}^{-1}\right)$, either kept in spring water (A) or reared in river water (B); white bars: control group, black bars: group SB, grey bars: group SC. Right: proportions of the dominant genera of bacteria characterised in trout, either kept in spring water (C) or reared in river water (D). 

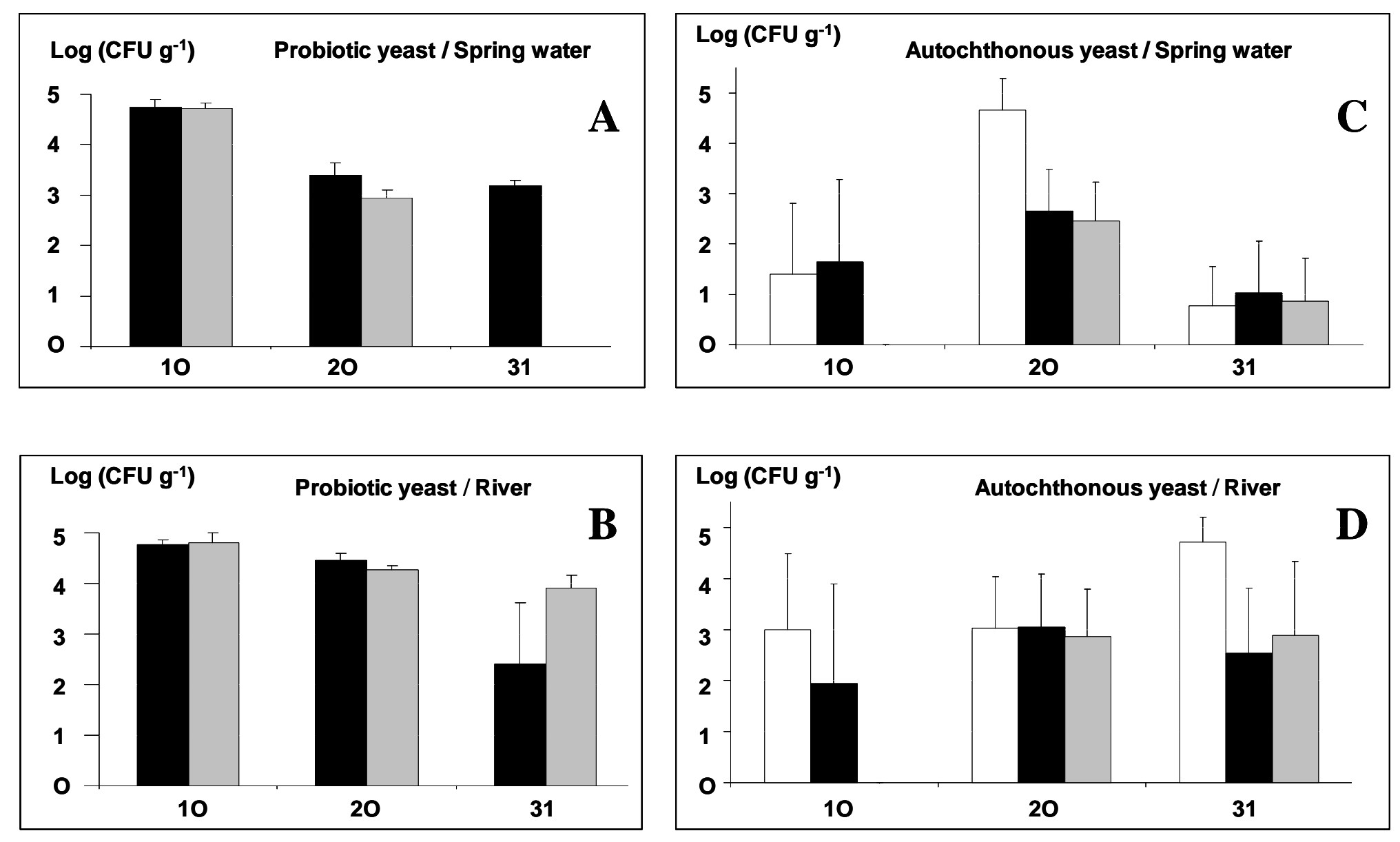

Fig. 2. Left: counts of probiotic yeast associated with the intestine of rainbow trout at 10, 20, and $31 \mathrm{dpsf}$ in $\log \left(\mathrm{CFU} \mathrm{g}^{-1}\right)$, either kept in spring water (A) or reared in river water (B); black bars: S. boulardii, grey bars: S. cerevisiae. Right: counts of autochthonous yeast, Debaryomyces hansenii, associated with the intestine of rainbow trout, either kept in spring water (C) or reared in river water (D). white bars: control group, black bars: group SB, grey bars: group SC. 

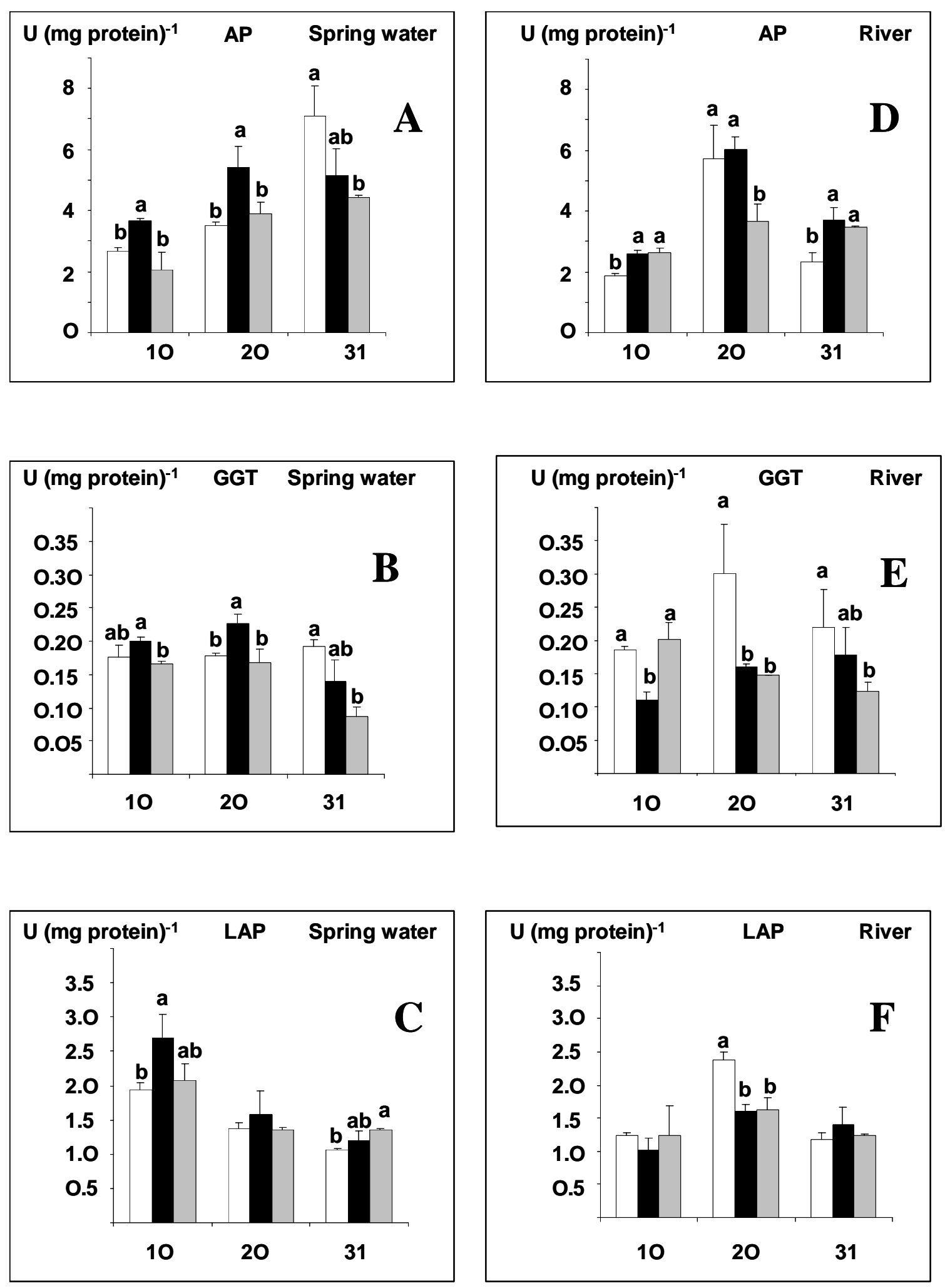

Fig. 3. Specific activity of the three BBM enzymes (in mg protein ${ }^{-1}$ ) in trout reared in spring water (left), or in river water (right) at 10, 20, and 31 dpsf; (A), (D): alkaline phosphatase; (B), (E): $\gamma$-glutamyl-transpeptidase; $(C)$, $(F)$ : leucine-aminopeptidase $N$; the letters a and b above the error bars indicate the significant differences. white bars: control group, black bars: group SB, grey bars: group SC. 

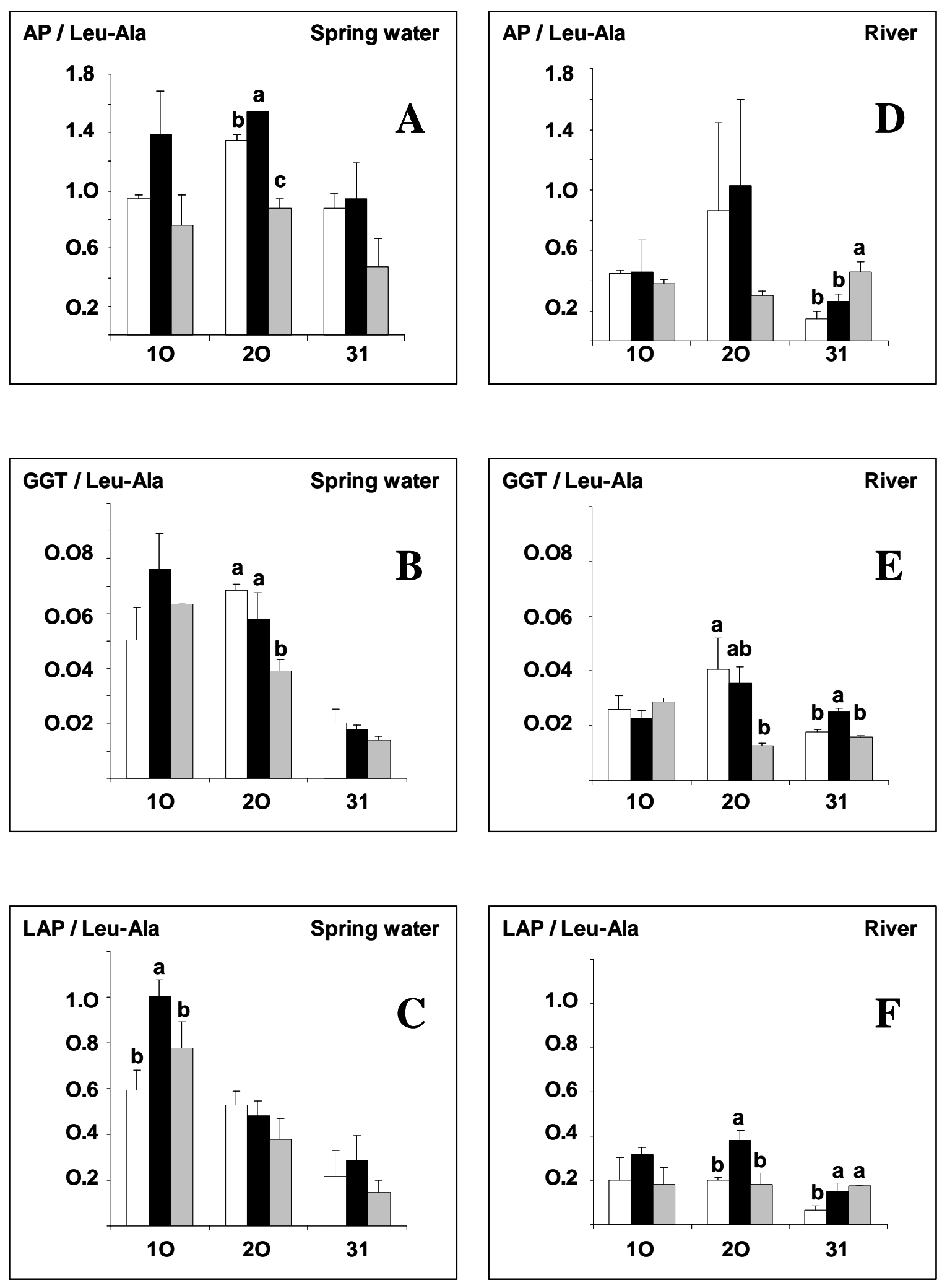

Fig. 4. Activity ratio to leucine-alanine peptidase of the three BBM enzymes in trout reared in spring water (left), or in river water (right) at 10, 20, and 31 dpsf; (A), (D): alkaline phosphatase; (B), (E): $\gamma$-glutamyl-transpeptidase; (C), (F): leucine-aminopeptidase $N$; the letters a, b and c above the error bars indicate the significant differences. white bars: control group, black bars: group SB, grey bars: group SC. 